\title{
Reusable sanitary towels: promoting menstrual hygiene in post-earthquake Nepal
}

\author{
Shyam Sundar Budhathoki, ${ }^{1}$ Meika Bhattachan, ${ }^{1}$ Paras K Pokharel, ${ }^{1}$ \\ Madhurima Bhadra, ${ }^{2}$ Edwin van Teijlingen ${ }^{3}$
}

\begin{abstract}
${ }^{1}$ School of Public Health \& Community Medicine, BP Koirala Institute of Health Sciences, Dharan, Nepal

${ }^{2}$ Dan Church Aid, Kathmandu, Nepal

${ }^{3}$ Faculty of Health \& Social Sciences Care, Bournemouth University, Bournemouth, UK
\end{abstract}

\section{Correspondence to}

Dr Shyam Sundar Budhathoki, School of Public Health \& Community Medicine, B P Koirala Institute of Health Sciences, Dharan 56700, Nepal ss.budhathoki@bpkihs.edu

Received 14 February 2016 Revised 17 June 2016 Accepted 20 July 2016 Published Online First 9 August 2016

\section{SLinked}

- http://dx.doi.org/10.1136/ jfprhc-2016-101605

\section{CrossMark}

$$
\begin{aligned}
& \text { To cite: Budhathoki SS, } \\
& \text { Bhattachan M, Pokharel PK, } \\
& \text { et al. J Fam Plann Reprod } \\
& \text { Health Care 2017;43:157- } \\
& 159 .
\end{aligned}
$$

\section{ABSTRACT}

It is a normal human tendency to 'run for your life' when an earthquake occurs. Adolescent girls and women of reproductive age leave their homes with only the clothes they are wearing to save their own and their families' lives. Immediate disaster relief aid with its (unintentional) lack of gender sensitivity has little or no materials for the appropriate management of menstrual hygiene. The biological needs of disaster-affected women will not change despite the dire need for basic food, shelter and security. Timely identification and preparation beforehand with appropriate and culturally sensitive techniques and locally available materials that are reusable can help introduce sustainable and acceptable means of managing menstrual hygiene in a crisis. The use of reusable sanitary towels is well accepted for menstrual hygiene management in non-disaster situations and is appropriate in post-earthquake relief in Nepal.

\section{INTRODUCTION}

The serious earthquake in Nepal on 25 April 2015 with a magnitude of 7.8 left thousands of people homeless. In the 14 hardest hit rural districts, more women $(55.2 \%)$ than men $(44.8 \%)$ were affected. ${ }^{1}$

After the initial search, rescue and first aid, more long-term issues came to the forefront. One of the essential needs of the two million female survivors centred on menstrual hygiene requirements, but this was low on the list of priorities. ${ }^{2} 3$ Menstrual hygiene requirements are often overlooked in displaced populations. ${ }^{4}$

\section{MENSTRUATION AS A TABOO}

Women's rights to reproductive health have been reaffirmed by the United Nations as an individual human rights issue. $^{5}$ Today there are places in Nepal where silence, shame and stigma surround menstruation and menstrual hygiene, suggesting a need for social change and further attention at the political level. ${ }^{6}$

Menstruation is considered to be dirty by many Nepalese, resulting in women being isolated and prohibited from carrying out rituals (entering temples, attending auspicious occasions) and certain household tasks as they are not permitted to enter the kitchen. This discrimination of untouchability varies among ethnic groups, cultures and communities. ${ }^{6}$ The most extreme example practised in rural western Nepal is isolating women and girls in rudimentary huts outside their homes, considering them untouchable until the seventh day of their menses (an outlawed practice known as Chhaupadi). ${ }^{7}$ The earthquake has shown the vulnerability of affected women with regard to menstrual hygiene and highlighted the taboo aspects. This taboo has silenced discussions on the topic in many cultures, as it is considered a strictly private matter that is shameful to discuss. ${ }^{2}$

\section{VULNERABILITY OF MENSTRUATING WOMEN AND ADOLESCENT GIRLS DURING DISASTERS}

Menstruation-related problems are some of the issues suffered by women of reproductive age affected by disasters in addition to physical injuries, shortage of food, lack of water, diseases, malnutrition, unemployment, harassment, crimes, lack of clothing, lack of privacy, gender-based violence, problems finding fuel wood, lack of toilets, eviction from their homes, and destruction of their houses. ${ }^{8}$ To address the immediate needs of people affected by the earthquake, many internal and external development partners 
supported Nepal through the provision of food, tents, general supplies and medications. Little attention was paid to menstrual hygiene while the efforts were being made to distribute supplies for the basic needs of food, shelter, protection and health. The existing cultural taboos surrounding menstruation practices further added to this situation, and menstrual hygiene needs remained an under-addressed issue. ${ }^{23}$

Unfortunately, the earthquake has not only dampened the hopes of improving education among females, but has also resulted in a vicious cycle of decreased attendance at school during menstruation. Moreover, the earthquake has led to an economic crisis, so most women and girls in rural areas do not have sufficient funds to buy pads and/or access to sanitary products. Those who cannot afford to buy sanitary pads resort to reusing materials such as old rags, leaves and toilet paper. In some instances, when these things are not available, they may not use anything at all. ${ }^{9}$ Infections such as lower reproductive tract infections, urinary tract infections and adverse pregnancy outcomes can result from the use of unhygienic materials, as the association between menstrual hygiene and reproductive health are strong. ${ }^{10}$

With $82 \%$ of females residing in a patriarchal society, with its disparity in education, human rights and socioeconomic status, women's freedom to choose and decide about their basic needs is limited, making them vulnerable to the challenges of menstrual hygiene management that are brought about by disasters. ${ }^{11}$

\section{WOMEN'S HYGIENE: NEED OF THE HOUR IN NEPAL}

While the government had called for and provided various necessities such as food, water, tents and clothes, the biological needs of female survivors in earthquake-affected areas were under-prioritised. Various international non-governmental organisations and national non-governmental organisations working to improve reproductive health had been providing disposable sanitary pads. However, using disposable sanitary pads can be a financial and environmental burden especially when proper waste management is not in place. ${ }^{12}$ During and immediately after disasters, local waste management can be a great challenge.

Studies have shown that more than half of adolescent school girls use cloth as menstrual pads in rural and peri-urban areas. ${ }^{13}$ Due to the increased accessibility and affordability of commercial sanitary pads, more affluent urban women have switched to them. ${ }^{14}$ A quarter $(25 \%)$ of the Nepalese population lives below the poverty line. This highlights the need to focus on economic status during disasters, as a packet of 10 pads costs, on average, US\$1.00 (NPR 60-140), which is more than the daily income of many adults, forcing poor women to resort to other means of protection during menstruation. ${ }^{15}$ This is in agreement with a study reporting that an overwhelming majority $(97 \%)$ of women resort to reusable materials, especially cloths, for menstrual hygiene in low-income countries. $^{16}$

At times of disaster (and other times as well) it seems reusable sanitary towels are an appropriate solution, with materials being scarce because of a disrupted market and limited resources. The reusable sanitary towel is appropriate for displaced populations, as it is user friendly, culturally acceptable, available and affordable. ${ }^{4}$

\section{REUSABLE SANITARY TOWELS: RESPONSIBILITY AND RESPONSE GO HAND IN HAND}

A group of academics working as volunteers in three cities, Kathmandu, Pokhara and Dharan, responded to the neglected needs of women and adolescent girls under a local initiative around reusable sanitary pads. The local kit contains four pieces of cotton cloth, two undergarments and one bar of soap sealed in a biodegradable bag (figure 1). Given the availability of water, these were expected to last for a year. ${ }^{17}$

Studies have shown that the reusable sanitary pads initiative has a positive effect on school attendance of adolescent girls and it is the preferred choice. ${ }^{18}$ The use of reusable pads in post-earthquake Nepal addresses relief needs from an equity angle using a targeted approach, with use of local resources, opportunity for local volunteers to make a contribution to local needs, and minimal or no waste generated. While a sustainable plan is yet to be put in place at the national level, the reusable sanitary pads initiative has addressed some of the immediate needs in a culturally sensitive, technologically appropriate way at very minimal cost using local resources, which is in line with the principles of primary healthcare. ${ }^{19}$ This approach is not new; however, probably because of lack of preparedness, the basic needs of women that can be addressed with simple solutions/items may have been overlooked. ${ }^{4}$ Further research is needed to ensure that future disaster preparedness plans cover post-disaster menstrual hygiene.

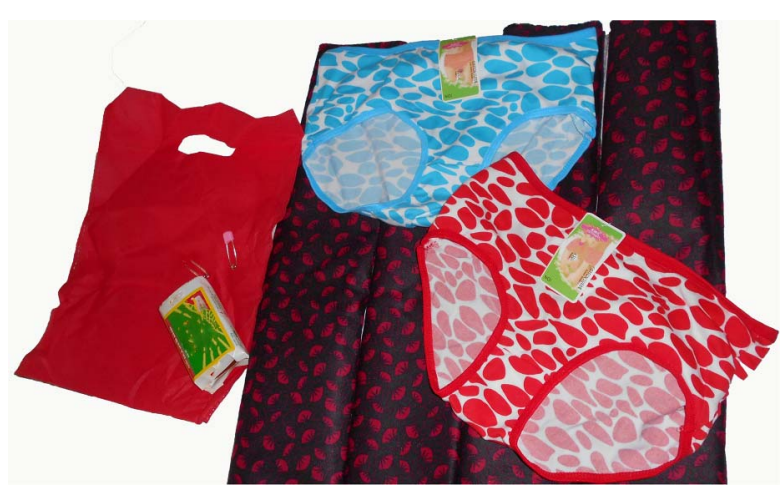

Figure 1 Contents of the reusable sanitary pad kit (four pieces of reusable cloth, two undergarments, one bar of soap and one biodegradable bag). 


\section{CONCLUSION}

Being prepared for natural disasters is the key to minimising their often devastating effects. Despite years of disaster management planning, post-disaster relief during the 2015 earthquake seemed relatively poor, especially in terms of addressing the menstrual hygiene of the affected women and girls. After the immediate search for survivors and first aid, more mundane issues need to be urgently addressed, such as those surrounding menstrual hygiene. Reusable sanitary towels have been recommended in the literature for use in displaced populations. The use of locally available, reusable and biodegradable materials is eco-friendly and empowering, as well as being a sustainable and culturally appropriate method for menstrual hygiene management in emergency situations. The current experience of addressing menstrual hygiene needs reflects a possible gap in practice even with an intervention that may be readily available, economically viable, socially acceptable and culturally appropriate.

Twitter Follow Shyam Sundar Budhathoki at@ShyamSuBu Competing interests None declared.

Provenance and peer review Not commissioned; externally peer reviewed.

\section{REFERENCES}

1 UN Office for the Coordination of Humanitarian Affairs, UN Resident and Humanitarian Coordinator for Nepal. Nepal: Earthquake 2015 Situation Report No.20 (as of 3 June 2015). Reliefweb. 2015 (cited 7 October 2015). http://reliefweb.int/ report/nepal/nepal-earthquake-2015-situation-report-no20-3june-2015

2 Thacker P. After earthquake in Nepal, sanitary menstruation practice at risk [Internet]. New York Times 2015 (cited 15 May 2015). http://nytlive.nytimes.com/womenintheworld/2015/05/01/ after-earthquake-in-nepal-sanitary-menstruation-practices-at-risk/

3 Lee B. Nepal earthquake: push for immediate relief leaves menstrual hygiene behind [Internet]. International Business Times 2015 (cited 8 May 2015). http://www.ibtimes.com/nepalearthquake-push-immediate-relief-leaves-menstrual-hygienebehind-1905601

4 Sommer M. Menstrual hygiene management in humanitarian emergencies: gaps and recommendations. Waterlines 2012;31:83-104.
5 United Nations. Women's Rights are Human Rights. Restructuring World Politics: Transnational Social Movements, Networks, and Norms. New York \& Geneva: United Nations Human Rights, Office of the High Commissioner, 2014:96-127.

6 Ranabhat C, Kim C-B, Choi EH, et al. Chhaupadi culture and reproductive health of women in Nepal. Asia-Pacific J Public Heal 2015;27:785-795.

7 Sanjel S. Gender-based violence: a crucial challenge for public health. Kathmandu Univ Med J (KUMJ) 2013;11:179-184.

8 Azad AK, Hossain KM, Nasreen M. Flood-induced vulnerabilities and problems encountered by women in northern Bangladesh. Int J Disaster Risk Sci 2013;4:190-199.

9 Plan International. Stigmas surrounding menstruation detrimental to girls' future [Internet]. 2015 (cited $10 \mathrm{Nov}$ 2015). https://plan-international.org/stigmas-surroundingmenstruation-detrimental-girls\%E2\%80\%99-futures

10 Biran A, Curtis V, Gautam OP, et al. Menstrual Hygiene. Background Paper on Measuring WASH and Food Hygiene Practices-Definition of Goals to be Tackled Post 2015 by the Joint Monitoring Programme. 1st edn. London: London School of Hygiene and Tropical Medicine, 2012:81.

11 Mahat I. Women's development in Nepal: the Myth of empowerment. Prax Fletcher J Int Dev 2003;XVIII:67-72.

12 Jamieson S. Stinking 10,000 tonne pile of rubbish in Great Heck, Yorkshire investigated by Environment Agency. Yorkshire: The Telegraph, 2015.

13 Oster EF, Thornton RL. Menstruation, sanitary products and school attendance: evidence from a randomized evaluation. NBER Work Pap Ser 2010;w14853:91-100.

14 Sapkota D, Sharma D, Budhathoki SS, et al. Knowledge and practices regarding menstruation among school going adolescents of rural Nepal. J Kathmandu Med Coll 2013;2:117-121.

15 Ministry of Health and Population [Nepal], New Era, ICF International. Nepal Demographic Health Survey. Kathmandu, 2011.

16 Tilley E, Bieri S, Kohler P. Sanitation in developing countries: a review through a gender lens. J Water Sanit Hyg Dev 2013;3:298-314.

17 Bhadra C. Report of the reusable sanitary Napkin Project in Nepal. Kathmandu, 2015.

18 Birat Nepal Medical Trust. A Report on Menstrual Hygiene Management Project in Morang, Nepal Birat Nepal Medical Trust. Kathmandu, 2015.

19 World Health Organization. The World health report: 2003: shaping the future. Geneva, World Health Organization, 2003.

\section{Letters to the Editor}

Letters to the Editor are welcome and generally should not exceed 600 words or cite more than five references. For comments on material published in the most recent issue of the journal, correspondence should be received within 4 weeks of dispatch of that journal to be in time for inclusion in the next issue. When submitting letters correspondents should include their job title(s) and their work affiliations(s)/contact address(es). A statement on competing interests should also be submitted for all letters. Letters may be submitted to the Journal Editor or to the Journal Editorial Office (details on the Editorial Board page). 